\author{
Ángela Alonso-Ovies \\ Gabriel Heras La Calle $\mathbb{B}$
}

\section{ICU: a branch of hell?}

Received: 31 July 2015

Accepted: 7 August 2015

Published online: 4 September 2015

(C) Springer-Verlag Berlin Heidelberg and ESICM 2015

Electronic supplementary material The online version of this article (doi:10.1007/s00134-015-4023-7) contains supplementary material, which is available to authorized users.

\author{
Á. Alonso-Ovies (®) \\ Intensive Care Unit, Hospital Universitario de Fuenlabrada, \\ Madrid, Spain \\ e-mail: a.alonso@salud.madrid.org \\ G. Heras La Calle (®) \\ Intensive Care Unit, Hospital Universitario de Torrejón, Torrejón \\ de Ardoz, Madrid, Spain \\ e-mail: gabihache@hotmail.com
}

\section{Á. Alonso-Ovies · G. Heras La Calle \\ The Research Project Humanizing Intensive Care (Proyecto \\ HU-CI), Spain, http://www.humanizingintensivecare.com/}

A few days ago I watched an interview on national television with a rising celebrity (a politician). Months ago, this person had sustained extremely serious, life-threatening injuries in a traffic accident that had led to a prolonged stay in ICU. When the show's host asked her about her experiences and memories of those dramatic moments, the interviewee defined the ICU as a "branch of hell" ("the ICU is a branch of hell, and people that have been there know what I mean...").

This categorical statement affected and outraged me. Gratitude that the interviewee subsequently and repeatedly thanked the healthcare professionals who treated her during the whole process did not soften my first impression. It was only later, when I reviewed the interview on the Internet, that I thought about this issue in a more calm and impartial manner. The celebrity supported her statement with the following reasons: when she awoke in the ICU after being in coma during about 2 weeks, she related: "The problem is not the pain, the pain and the fear are. Sometimes the fear is worse that the pain, and the combination of fear with pain... There was a time when I thought I was dying, and, above all, there came a time when I already wanted to die...".

For decades we have improved our care of critically ill patients, those who are torn between life and death, saving or prolonging lives; lives that a few years ago would have been lost. We dedicate our efforts and capacities to develop and implement new treatments and highly sophisticated support and monitoring systems that help us to improve the survival and quality of life of our patients. We spend many hours of our lives watching over the sick that are in our care. We research, publish, learn, teach..., but despite all this, the vision that many patients have of their passage through the ICU is sadly that they are in a "branch of hell".

There are many questions we should be asking: What moves a person who has been saved from almost certain death to make these statements? What did the patients feel during their hospitalization in an ICU? Do we care or worry about what patients feel? What are we doing wrong? What can we do to improve? Do we want to improve?

Intensive care units are nowadays probably the paradigm of the "dark side" of modern medicine, where mechanization has displaced the patient; this person is not seen as a human being who feels and suffers, but as a complex problem to solve. So ICU is probably a place where it is easy to identify the "dehumanization" of healthcare. It is necessary to implement a complete turnaround. We must claim and restore the prominence of the human being in healthcare, combined, of course, with scientific and technical advances that will help us to continue prolonging lives. 
The first step will probably be knowing what the critically ill patients feel, what they perceive, what is hurting them during their stay in the ICU. Numerous publications have been written on the subject, it is not a new issue; but despite the passing time, the perceptions and feelings of patients have still essentially not changed. It is difficult to understand how we have not been able to give sufficient importance to this aspect of care, but it is vital for patients. It is also difficult to understand why our patterns of behavior with patients in the ICU have not substantially changed to give priority to the satisfaction of their needs and demands, to the greatest extent possible.

The feelings of patients admitted to an ICU, if they have not lost their cognitive abilities or when they have recovered, are nothing unusual. These feelings are the same that any of us, their doctors and nurses, would experience if we were in the "opposite" situation, i.e., lying down in an ICU bed.

The team of professionals, patients, and families that are part of the "Research Proyect Humanizing Intensive Care (Proyecto HU-CI)", aware of this problem, tried to capture in a simple table the facts which cause suffering to our patients and what the possible solutions are. We do not intend to create a complicated algorithm of management nor reinvent the wheel. We just want to make available to all professionals working in an ICU a simple tool (of reference), an instrument to keep in mind each day at the time of attending to human beings who are under our care (see electronic supplementary material, ESM 1).

Fortunately, scientific knowledge, technology, and skills will be further developed in the coming years. Let's try to develop our "human" side at the same time. Only this will ensure that our ICU will be proclaimed as a "branch of life". It would be enough just to make the decision and start.

\section{Compliance with ethical standards}

Conflicts of interest The authors declare no conflict of interest. 